\title{
Impact of children's respiratory allergies on caregivers
}

\author{
G. Majani1, I. Baiardini2, A. Giardini1, M. Pasquali2, M. Tiozzo1, M. Tosca2, \\ C. Cosentino2, S. La Grutta3, G.L. Marseglia4, G.W. Canonica2
}

ABSTRACT: Impact of children's respiratory allergies on caregivers. G. Majani, I. Baiardini, A. Giardini, M. Pasquali, M. Tiozzo, M. Tosca, C. Cosentino, S. La Grutta, G.L. Marseglia, G.W. Canonica.

Background. Despite the great attention that has been paid to HRQoL in children with respiratory allergy, few studies have addressed this aspect in relation to caregivers. The aim of our study was to evaluate the impact of childhood respiratory allergies on caregivers by means of a new method.

Methods. 119 parents of children suffering from allergies (75 suffering from asthma and 44 suffering from rhinitis) were recruited from three Italian Allergy Units. Parents were asked to complete the Disease Impact On Caregiver (DIOC), a new non disease specific questionnaire, validated on the Italian population. The questionnaire consists of $\mathbf{3 1}$ items grouped in four factors (Performance, Personal gratification, Psychophysical endurance, Socio-emotional domain) and covers the life aspects that could be affected by the assistance duties towards an ill family member.

Results. Child's asthma resulted to have a worse impact on many aspects of a parents' life than rhinitis. Differences resulted to be statistically significant in 19 aspects out of the 31 assessed. The worse impact of asthma versus rhinitis was confirmed in the following domains: Performance (24.0 \pm 18.2 vs 11.5 \pm 17.8$)$, Personal gratification $(26.3 \pm 20.5$ vs $12.1 \pm 16.5)$ and Psychophysical endurance (35.0 \pm 24.8 vs $18.8 \pm 21.7)$. In the Socio-emotional domain no difference emerged.

Conclusions. Compared to parents of rhinitics, parents of asthmatic children appear to be more compromised in their resistance to stress, mood, emotional stability, amount of spare time and leisure activities. Our results suggest the need of giving the due attention to these problems both in clinical practice and in research, in order to avoid possible interferences of the caregiver's distress in the optimization of treatment outcome. Monaldi Arch Chest Dis 2005; 63: 4, 199-203.

Keywords: Respiratory allergy, child, caregiver, disease impact.

1 Psychology Unit, Fondazione S. Maugeri, Clinica del Lavoro e della Riabilitazione, IRCCS, Istituto Scientifico di Montescano (PV) 2 Allergy and Respiratory Diseases, DIMI, Dept. of Internal Medicine, University of Genoa

3 Allergy Unit, Children Hospital, ARNAS-Palermo, Palermo

4 Department of Pediatric Sciences, University of Pavia, IRCCS Policlinico San Matteo, Pavia, Italy.

Correspondence: Dr. Giuseppina Majani, Fondazione S. Maugeri, Servizio di Psicologia, Isitituto Scientifico di Montescano, 27040 Montescano (PV) - Italy; e-mail: gmajani@fsm.it

\section{Introduction}

Beside the conventional biomedical parameters, in the last decade Health Related Quality of Life (HRQoL) has become an important indicator of medical outcome. Within this field, a multidimensional understanding of illness burden on patient and family is nowadays gaining attention in order for appropriate and effective treatment strategies to be designed and applied [1-2].

The impact of a chronic disease on the caregiver always deserves great attention, but it becomes a central issue when dealing with paediatric patients. Illness management in this case must always be shared by parents and child.

In the last years, several questionnaires have been developed in order to explore caregivers' reactions to a child's illness [3-6].

In respiratory allergies this aspect of care has been seldom addressed providing data on HRQoL in parents of asthmatic children [7-9]. Townsend showed that the primary caregivers have stated limitations in daily activities and distress as results of their child's asthma [10]. On the basis of these results, Juniper and co-workers [11] developed the PACQLQ (Paediatric Asthma Caregiver's Quality of Life Questionnaire), a specific instrument, designed to explore the impact of paediatric asthma on parents' every day life and emotions.

Osman et al. [9] administered the PACQLQ to 62 parents of pre-school asthmatic children. Caregivers' age $(<30)$ and a low socioeconomic status had a significant negative impact on QoL scores, moreover as child symptoms improved or worsened, parental PACQLQ scores changed coherently.

Studies considering the burden of allergic rhinitis on parents are not yet available.

The aim of our study was to apply a new Italian questionnaire (Disease Impact On Caregiver - DIOC) on parents of children suffering from allergic respiratory diseases, in order to compare the burden of asthma and rhinitis on parents' daily life. 


\begin{tabular}{|c|c|c|c|c|}
\hline \multicolumn{2}{|c|}{$\begin{array}{l}\text { Subjects and procedure } \\
\text { Data was collected in three Italian Allergy } \\
\text { Units (Genoa, Pavia, Palermo). To be eligible for } \\
\text { the study, participants had to be parents of a child }\end{array}$} & \multicolumn{3}{|c|}{$\begin{array}{l}\text { clinic, parents were assessed and informed written } \\
\text { consent was obtained. The presence of any chron- } \\
\text { ic disease (e.g. diabetes, epilepsy, major neuropsy- } \\
\text { chiatric disorders) other than respiratory allergy } \\
\text { was an exclusion criterion. Recent major events in }\end{array}$} \\
\hline \multicolumn{5}{|c|}{ Table 1. - Sample characteristics } \\
\hline & & $\begin{array}{l}\text { Rhinitis group } \\
\qquad(\mathrm{n}=\mathbf{4 4 )}\end{array}$ & $\begin{array}{l}\text { Asthma group } \\
\qquad(n=75)\end{array}$ & $p$ \\
\hline \multicolumn{5}{|c|}{ Childrens' characteristics } \\
\hline Gender & $\begin{array}{l}M \\
F\end{array}$ & $\begin{array}{l}24(56 \%) \\
20(44 \%)\end{array}$ & $\begin{array}{l}41(55 \%) \\
34(45 \%)\end{array}$ & $\begin{array}{l}\mathrm{ns} \\
\mathrm{ns}\end{array}$ \\
\hline Age & & $7.8 \pm 3.4$ & $7.1 \pm 3.3$ & ns \\
\hline \multicolumn{5}{|c|}{ Caregivers' characteristics } \\
\hline Gender & $\begin{array}{l}\mathrm{M} \\
\mathrm{F}\end{array}$ & $\begin{array}{c}9(21 \%) \\
35(79 \%)\end{array}$ & $\begin{array}{l}9(12 \%) \\
66(88 \%)\end{array}$ & $\begin{array}{l}\mathrm{ns} \\
\mathrm{ns}\end{array}$ \\
\hline Age & & $38.0 \pm 5.3$ & $36.1 \pm 6.4$ & $\mathrm{~ns}$ \\
\hline Marital status & $\begin{array}{l}\text { Single } \\
\text { Married }\end{array}$ & $44(100 \%)$ & $\begin{array}{c}6(8 \%) \\
69(92 \%)\end{array}$ & $\begin{array}{l}\mathrm{ns} \\
\mathrm{ns}\end{array}$ \\
\hline Years of education & $\begin{array}{l}0-5 \\
6-8 \\
9-13 \\
\text { more than } 14\end{array}$ & $\begin{array}{l}1(3 \%) \\
12(27 \%) \\
26(59 \%) \\
5(11 \%)\end{array}$ & $\begin{array}{c}4(5 \%) \\
30(40 \%) \\
35(47 \%) \\
6(8 \%)\end{array}$ & $\begin{array}{l}\mathrm{ns} \\
\mathrm{ns} \\
\mathrm{ns} \\
\mathrm{ns}\end{array}$ \\
\hline Employment status & $\begin{array}{l}\text { employed } \\
\text { housewife } \\
\text { retired }\end{array}$ & $\begin{array}{c}31(70 \%) \\
12(27 \%) \\
1(3 \%)\end{array}$ & $\begin{array}{c}40(53 \%) \\
32(43 \%) \\
3(4 \%)\end{array}$ & $\begin{array}{l}\mathrm{ns} \\
\mathrm{ns} \\
\mathrm{ns}\end{array}$ \\
\hline
\end{tabular}

\section{Negative impact}

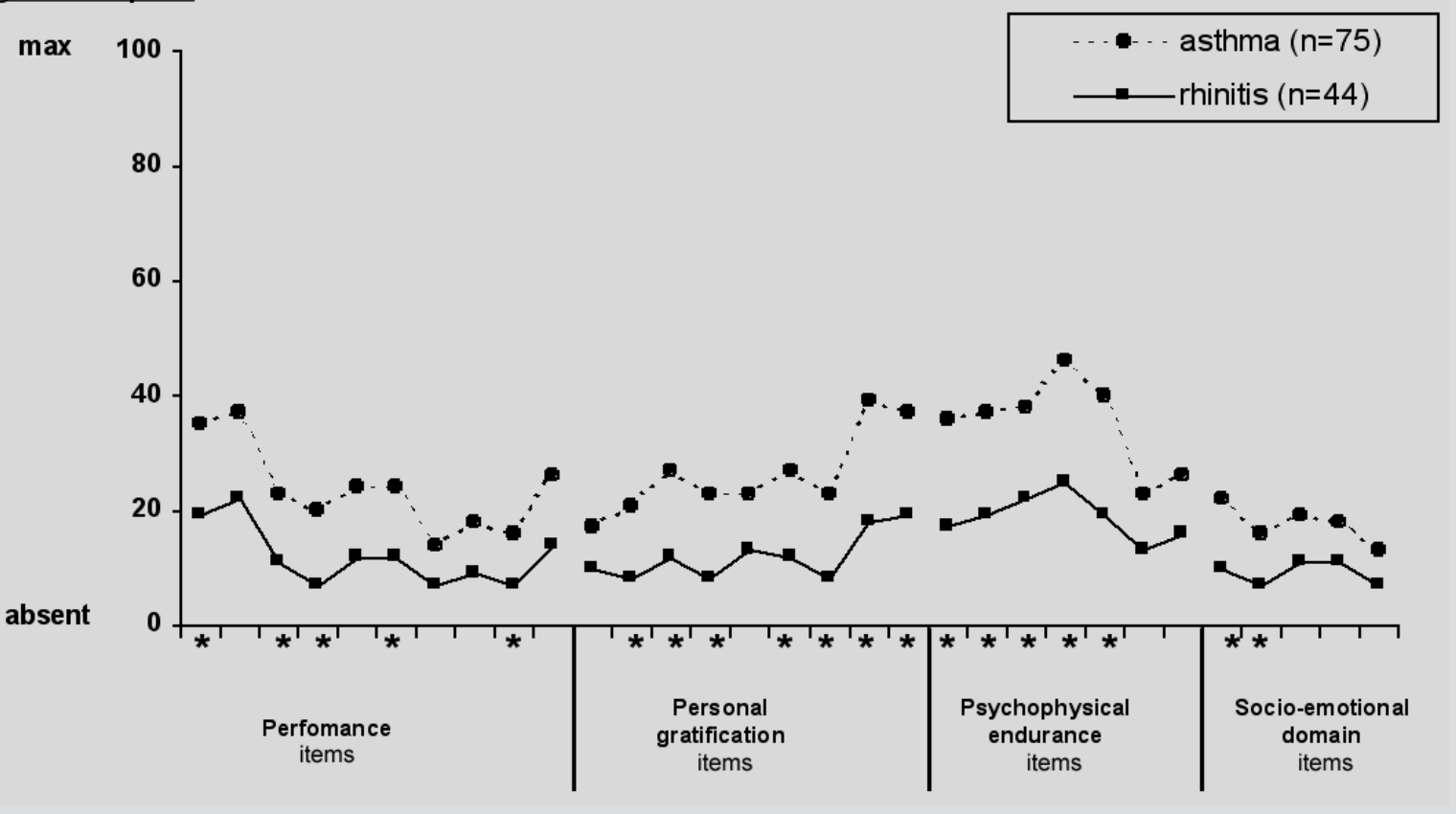

Fig. 1. - DIOC items comparison between caregivers of children with asthma and caregivers of children with rhinitis. ${ }^{*} \mathrm{p}<0.01$ 
parent's or in family's life (such as divorce, death of relatives, changes in lifestyle) were exclusion criteria as well.

One hundred and twenty-five parents of these children were recruited over a three-month period, during the pollen season. The presence of a respiratory allergy was ascertained through routine diagnostic criteria: positive clinical history and skin prick test positivity to the common allergens. The prick tests were performed according to international guidelines [12] with commercial standardised extracts of the following allergens: house dust mites, grass, parietaria, cat dander, dog dander, birch, olive, hazelnut, cypress, Alternaria and Cla- dosporium. Tests were carried out on the forearm, using positive (histamine 1\%) and negative (saline) controls for comparison. The results were expressed as the mean of the major diameter of the wheal plus it's orthogonal. Reactions greater than $3 \mathrm{~mm}$ were considered positive.

Persistent allergic rhinitis was clinically diagnosed, following international guidelines [13]. The diagnosis of asthma was based on clinical history of recurrent attacks of shortness of breath, chest tightness, wheezing, nocturnal awakenings, cough within the past two years and/or actual dyspnea and/or wheezing at clinical examination. Pulmonary function test (PFT) showing a $\mathrm{FEV}_{1}$ less

Table 2. - Comparison between DIOC item scores of parents of rhinitic children and DIOC item scores of parents of asthmatic children (means, standard deviations and $p$ values are reported)

$\underset{(n=44)}{\text { Parents of rhinitic children }} \quad \begin{gathered}\text { Parents of asthmatic children } \\ (n=75)\end{gathered}$

\section{Performance}

Amount of sleep

Quality of sleep

Mental efficiency

Problem solving ability

Type of work

Organization of work

Professional role

Work productivity

Social Image

Financial situation

Personal gratification

Quality of food

Eating behaviour

Physical appearance

Physical mobility

Level of physical activity

Frequency of sexual intercourse

Quality of sexual intercourse

Amount of spare time

Leisure activities

Psychophysical endurance

Resistance to physical fatigue

Physical well being

Resistance to stress

Mood

$19.45 \pm 29.02$

$21.82 \pm 29.26$

$10.52 \pm 20.66$

$7.02 \pm 15.49$

$12.18 \pm 24.33$

$11.50 \pm 21.30$

$6.65 \pm 16.95$

$9.39 \pm 22.46$

$14.48 \pm 30.16$

$10.36 \pm 20.78$

$8.09 \pm 18.09$

$11.57 \pm 19.77$

$7.77 \pm 20.67$

$12.66 \pm 24.49$

$12.11 \pm 21.58$

$8.40 \pm 20.30$

$18.41 \pm 26.73$

$19.34 \pm 27.92$

$6.68 \pm 26.61$

$19.14 \pm 28.37$

$22.41 \pm 29.00$

$25.14 \pm 29.43$
$6.68 \pm 14.81$

$\begin{array}{lc}34.93 \pm 33.33 & .01 \\ 36.52 \pm 32.94 & \mathrm{~ns} \\ 23.17 \pm 28.10 & .006 \\ 19.69 \pm 23.92 & .001 \\ 23.79 \pm 30.20 & \mathrm{~ns} \\ 24.14 \pm 29.81 & .01 \\ 14.12 \pm 21.40 & \mathrm{~ns} \\ 18.01 \pm 22.92 & \mathrm{~ns} \\ 16.40 \pm 23.63 & .007 \\ 26.25 \pm 30.67 & \mathrm{~ns}\end{array}$

$17.38 \pm 23.58$

ns

$20.51 \pm 27.79$

.004

.001

$26.69 \pm 30.26$

.002

$22.79 \pm 28.95$

ns

$22.11 \pm 28.60$

.002

$22.52 \pm 27.83$

.002

$38.52 \pm 34.93$

.001

.003

Emotional stability

$35.59 \pm 34.30$

.001

$36.69 \pm 32.23$

.003

$37.55 \pm 31.92$

$45.84 \pm 34.15$

.01

$19.45 \pm 22.21$

$39.84 \pm 34.46$

.001

$12.81 \pm 23.71$

$23.39 \pm 30.10$

.0001

$16.43 \pm 33.48$

$26.37 \pm 29.34$

ns

ns

Socio-emotional domain

Couple relationship

$10.41 \pm 18.81$

$21.55 \pm 27.80$

.01

$7.27 \pm 14.14$

$15.99 \pm 22.66$

.01

Relationship with other members of the family

$11.09 \pm 21.69$

$18.58 \pm 26.97$

$11.09 \pm 21.39$

$18.01 \pm 24.88$

$7.46 \pm 14.42$

$13.33 \pm 22.55$

Relationship with colleagues ns

ns

ns 


\section{Negative impact}

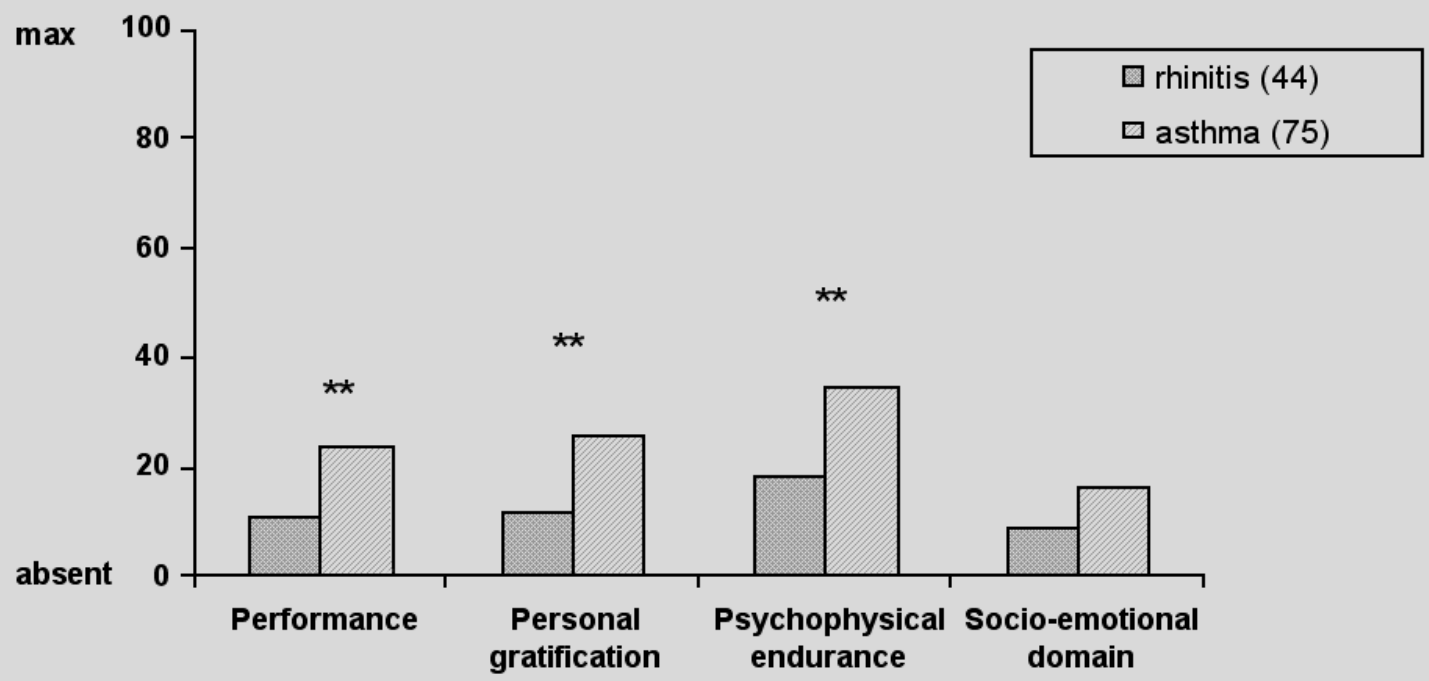

Fig. 2. - DIOC factors comparison between parents of children with asthma and parents of children with rhinitis. $* * \mathrm{p}<0.0001$

than $80 \%$ of predicted value with a reversibility of at least $12 \%$ after salbutamol or a positive methacholine $(\mathrm{MCh})$ challenge with a provocation dose $\left(\mathrm{PD}_{20}\right)$ of $1200 \mu \mathrm{g}$ or less were also used for diagnosis.

\section{Instrument}

The Disease Impact On Caregiver (DIOC), developed by the Psychology Unit of the Scientific Institute of Montescano, is a new questionnaire recently validated on the Italian population [14-15]. The DIOC resulted in good psychometric properties (criterion and construct validity, test-retest reliability, internal reliability and responsiveness). The instrument consists of 31 items grouped by factor analysis into 4 dimensions. For each item the primary caregiver is requested to assess, on a $10 \mathrm{~cm}$ horizontal visual analogue scale, the child disease impact on many aspects of daily life, that may be affected by the assistance duties towards an ill family member. Each score ranges from 0 (no negative impact) to 100 (maximum negative impact). The higher the scores the more negative the impact.

\section{Statistical analyses}

Descriptive analyses were conducted considering the child's demographic characteristics (sex, and age) and parent's demographic characteristics (sex, age, marital status, years of education, and employment status). After dividing the parents in two groups according to diagnosis (rhinitis alone or asthma with or without rhinitis), $t$-test for unpaired samples and Chi-square test were adopted on demographic characteristics in order to verify the homogeneity of the two samples. DIOC item and factor scores of the two groups were compared by means of $t$-test for unpaired samples. A multivariate analysis was not necessary because of group homogeneity. For all the analyses, the $p$ value was set at 0.01 .

The statistical analyses were performed using the SPSS 11.0 statistical software package.

\section{Results}

Out of 125 questionnaires completed by the parents, 119 questionnaires were considered for the analyses, since 6 were incorrectly completed. Parents' and children's demographic characteristics are shown in table 1 . No significant statistical differences emerged in demographic characteristics between the two groups.

The comparison between DIOC item scores of rhinitics' and asthmatics' parents showed that the presence of children's asthma had a significantly heavier impact on a caregiver's life than rhinitis alone in many aspects of daily life (figure 1 and table 2).

The statistically significant worsening impact of asthma vs rhinitis was reconfirmed following the consideration of the DIOC factors: Performance $(24.0 \pm 18.2$ vs $11.5 \pm 17.8)$, Personal gratification $(26.3 \pm 20.5$ vs $12.1 \pm 16.5)$ and Psychophysical endurance $(35.0 \pm 24.8$ vs $18.8 \pm 21.7)$ (figure 2 ).

\section{Discussion}

The results of the present study highlight the impact of paediatric respiratory allergy on parent's every day life, as already demonstrated in recent research $[7,9,11]$. Parents of asthmatic children have to deal with demanding issues, both practical and psychological, connected to asthma manage- 
ment; in our sample these aspects seem to compromise mainly their resistance to stress, mood, emotional stability, amount of spare time and leisure activities. Conversely, our results have shown that rhinitis has a lighter impact than asthma: primary caregivers of asthmatics reported higher DIOC scores in almost every item and in three out of the four dimensions.

These differences in the two groups were mainly expected and are confirmed by clinical experience. But they also provide an important clinical clue: the low scores in parents' of rhinitics may stem from a general attitude to consider rhinitis as "not more than a cold" and therefore to underestimate and minimise the possible evolution of the disease through time.

Moreover the DIOC also detected caregivers' resources: in the Socio-emotional dimension, even if the two groups' profiles did differ in two items, the item scores were substantially low. This could be read as an indicator of the presence of effective interpersonal abilities and of a strong affective network, which supports caregivers independently from the disease severity. Health care professionals can obtain useful information from the DIOC in order to better focus their psychological support.

Some limits should be underlined: a control group is not available, but theoretically, since this assessment focuses on the subjective component of disease impact, no normative data on caregivers' of healthy subjects may be collected. Further studies may investigate the correlation between the DIOC and other validated tools.

In our study disease severity and follow-up were not considered, because of sample size; further studies may be performed. Moreover, even if the $p$ values underline relevant significant differences between the two groups, the high standard deviation of the scores carries a warning to be cautious when interpreting our results.

Finally, parents openly appreciated being asked about their personal difficulties and fatigue in taking care of their child. This can in turn improve the quality of communication between the primary caregiver and the medical staff, which is renowned as one of the strongest predictors of treatment adherence. The DIOC could also properly identify the caregivers' needs, thus helping clinicians in offering a focused and multidisciplinary intervention when necessary.

\section{References}

1. Canam C, Acorn S. Quality of life for family caregivers of people with chronic health problems. Rehabilitation Nursing 1999; 24: 192-96.

2. Sales E. Family burden and quality of life. Qual Life Res 2003; 12: 33-41.

3. Rossi Ferrario S, Baiardi P, Zotti AM. Update on the Family Strain Questionnaire: a tool for the general screening of caregiving-related problems. Qual Life Res 2004; 13: 1425-34.

4. Berg-Weger M, Tebb SS. Caregiver well-being: a strengths-based case management approach. J Case Manag 1998; 7: 67-73.

5. Weitzner MA, Jacobsen PB, Wagner H, Friedland J, Cox C. The Caregiver Quality of Life Index-Cancer (CQOLC) scale: development and validation of an instrument to measure the quality of life of the family caregivers of patients with cancer. Qual Life Res 1999; 8: 56-63.

6. Berdeaux G, Hervié C, Majda C, Marquis P. Parental quality of life and recurrent ENT infections in their children: development of a questionnaire. Qual Life Res 1998; 7: 501-12.

7. Dalheim-Englund AC, Rydstrom I, Rasmussen BH, Moller C, Sandman PO. Having a child with asthmaquality of life for Swedish parents. J Clin Nurs 2004; 13: 386-395.

8. Price MR, Bratton DL, Klinnert MD. Caregivers affect is a primary determinant of caregiver report of pediatric asthma quality of life. Ann Allergy Asthma Immunol 2002; 89: 540-1.

9. Osman, LM, Baxter-Jones ADG, Helmes PJ. Parents' quality of life and respiratory symptoms in young children with mild wheeze. Eur Respir J 2001; 17: 254-58.

10. Townsend M, Feeny DH, Guyatt, GH, Furlong WJ, Seip AE, Dolovich J. Evaluation of the burden of illness for pediatric asthmatic patients and their parents. Ann Allergy 1991; 67: 403-8.

11. Juniper EF, Guyatt GH, Feeny DH, Ferrie PJ, Griffith LE, Townsend M. Measuring quality of life in the parents of children with asthma. Qual Life Res 1996; 5: 27-34.

12. Dreborg S., Frew A. Position paper: Allergen standardization and skin tests. Allergy 1993;48 (suppl 14): 4982.

13. Bousquet J, Van Cauwenberge P, Khaltaev N. Allergic rhinitis and its impact on asthma (ARIA) (ARIA Workshop Report). J Allergy Clin Immunol 2001; 108: 147334.

14. Majani G, Baiardini I, Giardini A, et al. The impact of children's asthma and rhinitis on caregiver. J Allergy Clin Immunol 2000; 105: S317.

15. Tiozzo M, Giardini A, Majani G, et al. Presentazione del Disease Impact On Caregiver (DIOC): un nuovo questionario per la rilevazione del disagio del caregiver. Psicoterapia Cognitiva e Comportamentale 2002; 8: 233-46. 